\title{
Life History of the Pholcid Spider, Micropholcus fauroti (Simon, 1887) (Araneae: Pholcidae) in Egypt
}

\author{
Naglaa F. R. Ahmad and M. M. Abou-Setta \\ Plant Protection Research Institute, Agric. Res. Center, Giza, Egypt.
}

\begin{abstract}
Behavioral and biological aspects of the pholcid spider, Micropholcus fauroti (Simon, 1887) (Araneae: Pholcidae) at $26 \pm 2{ }^{\circ} \mathrm{C}$ and $75 \pm 10 \% \mathrm{RH}$ were studied. Female deposited its eggs in webbing basket, and carried it all around through eggs incubation period. Newly hatched spiderlings are very transparent and delicate. They stayed in the basket and molted inside or shortly after getting out of it. This spider went through eight spiderlings to reach adult as female and seven ones as male. First spiderling was noticed to molt for the following one without feeding. Second to fourth spiderlings were reared on Tetranychus urticae motile stages, while later ones on Ephestia kuehniella moths. Males developed faster than females during 187.53 and 208.81 days, respectively. Generation time expanded to 212.4 days. Adult females lived longer than males (i.e. 60.00 and 45.53 days, respectively). Life span averaged 268.8 and 233.1 days for females and males, respectively. Survival ratio of individuals reached maturity was $72 \%$. Sex ratio was 0.682 females/total. Females' fecundity was $68.26 \mathrm{eggs} / \mathrm{female}$. Female produced a mean of $4.02 \mathrm{sacs}$; each contained an average of $12.95 \mathrm{eggs} / \mathrm{sac}$. Mean number of eggs/sac was 13.22, 22.44, 14.51, 8.56 and $6.00 \mathrm{eggs} / \mathrm{sac}$ for first to fifth one, respectively. Intervals between egg sacs' deposition averaged 12.9 days. Mean consumption of T. urticae was 325.4 and 345.7 during second to fourth spiderlings for females and males, respectively. Obtained data indicated life table parameters of M. fauroti under studied conditions as mean generation time $(T)=232.2$ days, net reproductive rate $\left(\mathrm{R}_{\mathrm{o}}\right)=40.174$, intrinsic rate of increase $\left(r_{m}\right)=0.477$ per month and $\exp \left(r_{m}\right)=1.611$ individual/individual/month, as this organism is slow developing one. Mean consumption of E. kuehniella was 326.58 and 238.23 moths/individual, for female and male, respectively, during fifth spiderling to adult stage. Mean consumption of E. kuehniella was 175.1 and 69.8 moths for females and males, respectively, during adult stage longevity.
\end{abstract}

Key words: Micropholcus fauroti, Pholcidae, behavior, biology, life table parameters, prey consumption.

\section{INTRODUCTION}

Spiders play an important role in agricultural ecosystems. They are generalist predators feed on insects and some other arthropods. Biological aspects of spiders have received considerable attention.

Family: Pholcidae C. L. Koch (1850) (Araneae: Pholcidae) is one of the most diverse spider families (Huber, 2003). It was described by C. L. Koch (1850) including 80 genera and 1611 species over the world (World Spider Catalog: NMBE, 2017). Six genera and species have been recorded in Egypt (ElHennawy, 2006 and Huber \& El-Hennawy, 2007).

Pholcids are among the dominant web-building spiders in many tropical and subtropical areas, occupying a wide variety of habitats ranging from leaf-litter to tree canopy. Several species occur in caves and in close proximity to humans (Huber, 2005).

Micropholcus includes 15 species of which $M$. fauroti (Pholcus fauroti) (Simon, 1887) is the genus type. Species of this genus are pan-tropical ones that spread around the world (Huber et al., 2017). They distribute from Temperate Asia to Americas, Belgium, Germany, Africa, Laos, Myanmar, Thailand, Vietnam, Indonesia, Australia and Pacific (World spider catalog: NMBE, 2017). Barrion et al.
(2012) recorded M. fauroti on the island of Hainan (part of Southern China) with surrounding environments of irrigated rice fields.

General biology of spiders indicates going through egg stag followed by number of spiderlings before reaching maturity. Number of spiderlings of males and females can be similar or larger for females (Foelix, 2011).

Knowledge of pholcid spiders' life cycles is very scarce. The biology of $M$. fauroti has never been studied in any detail (Huber et al., 2017). This study aimed to report the life history as a first step to understanding its behavior and role in natural control. Possibly it could be used as agent for stored products pests. It seems be a suitable environment for its existence.

\section{MATERIALS AND METHODS}

Adult females of $M$. fauroti were collected from compound house building located in Cairo, Egypt, where it built very flimsy webs in the building corners.

Behavioral aspects of this spider were observed and reported herein. Biological study of the spider was performed under constant temperature of $26 \pm 2^{\circ} \mathrm{C}$ and $75 \pm 10 \%$ R.H. Newly hatched spiderlings were 
placed separately in plastic vials $(3 \mathrm{~cm}$ diameter x 5 $\mathrm{cm}$ height). Second to fourth spiderlings were fed, every two days, on motile stages of Tetranychus urticae. Later spiderlings and adult stages were fed on Ephestia kuehniella adults.

T. urticae culture was maintained under laboratory conditions on bean plants and E. kuehniella culture on wheat seeds germ.

Developmental stages and adults' life were observed daily. Different stages durations and consumption were determined and reported as well as female specific data.

\section{RESULTS AND DISCUSSION}

\section{Behavioral aspects:}

This species was recorded as new record from Egypt (Huber et al., 2017), although it was included in Egyptian List by El-Hennawy (2006). Pictorial spider stages and E. kuehniella moth predation sequence are presented in Figs. (1-8).

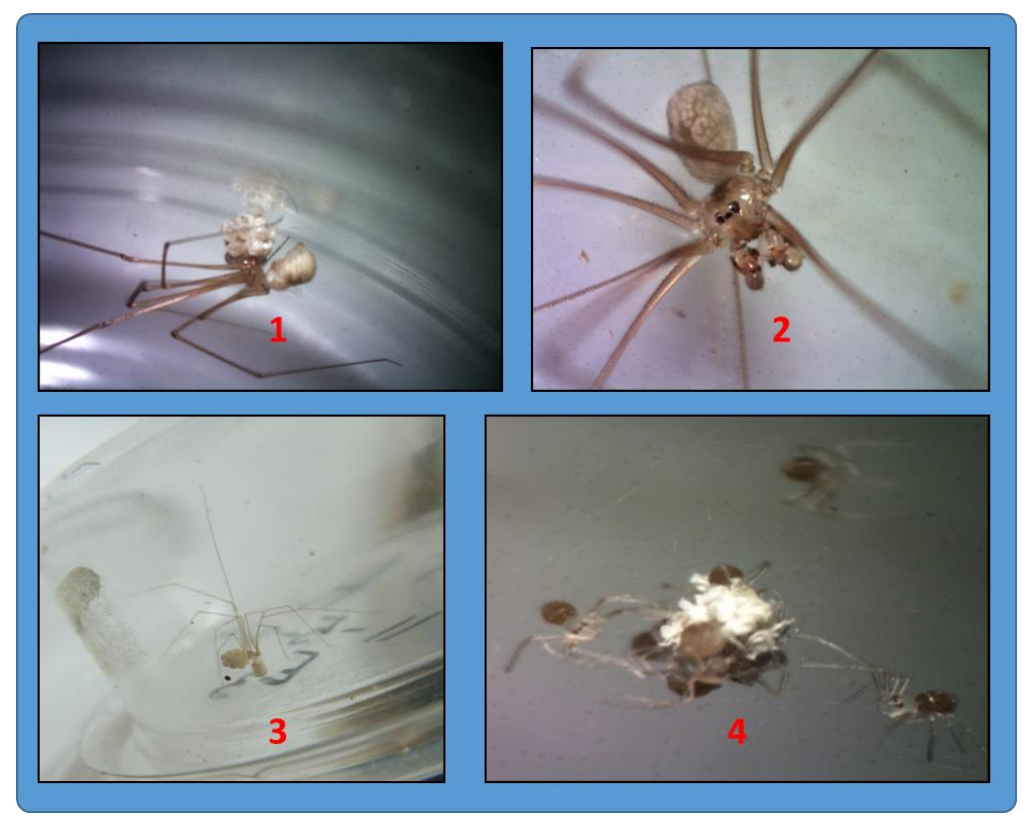

Figs. (1 -4). Micropholcus fauroti (Simon, 1887). $1 \& 3$ female carrying an egg sac. 2. male. 4. Newly hatched spierlings.

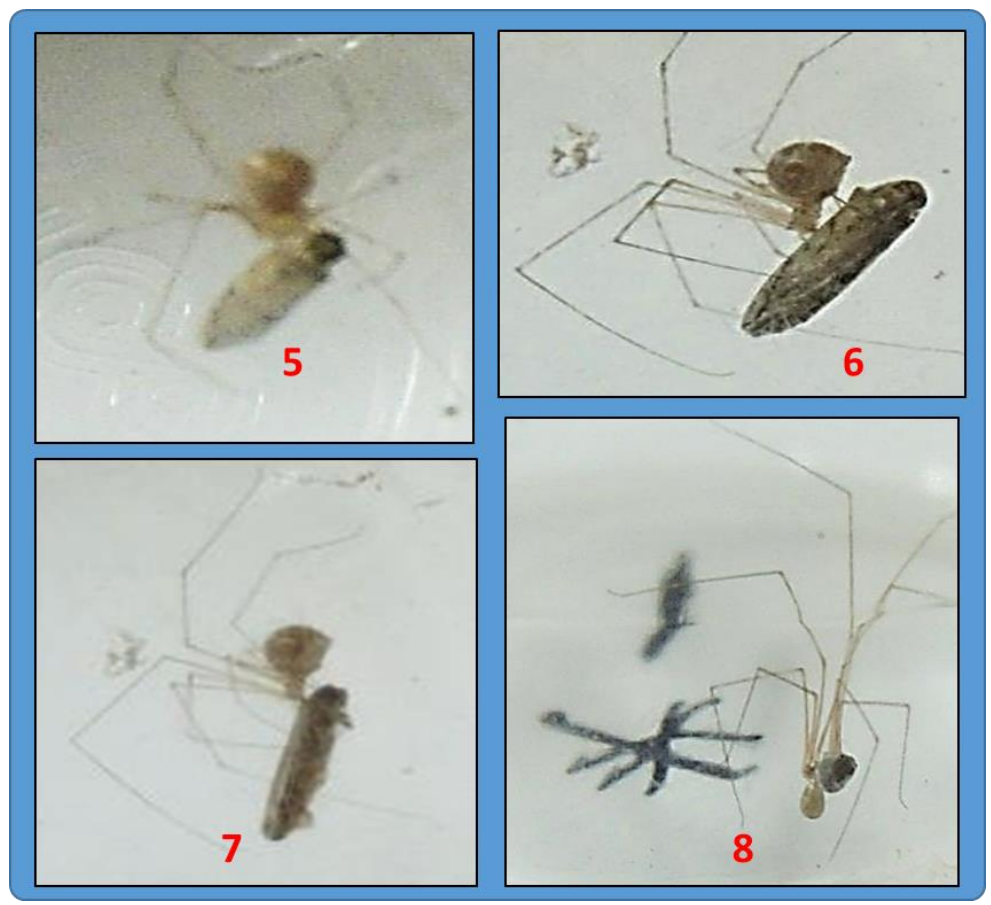

Figs. (5 - 8). Sequence of Micropholcus fauroti (Simon, 1887) female predation of Ephestia kuehniella moth. 
Although this species has a vast worldwide distribution as building hold one, it was not previously reared. Females deposited their eggs in a basket of webbing, and carried it all around through eggs incubation period (Figs. 1 and 3). Newly hatched spiderlings are very transparent and delicate (Fig. 5). These hatch stay in the basket and molt inside it or shortly after getting out of it without feeding on any prey. Males (Fig. 2) can mate for more than one time. They escape away from females after mating, otherwise they will be prayed on, if they were slugish. Early stages prefer to hunt small ants. They can hunt them in a wonderful way in a very short time. Also, they can hunt small flying insects which are prober to their size. Later stages can hunt larger prey type. Activity area of this species is relatively small. More than one individual can occur in small area.

\section{Biological aspects:}

Biological aspects of $M$. fauroti, at $26 \pm 2^{\circ} \mathrm{C}$ and $75 \pm 10 \%$ R.H. reared on T. urticae motile stages and E. kuehniella moths are presented in Tables (1-3). Durations in days of different stages are presented in Table (1). This spider went through eight spiderlings to reach adult as female and seven ones as male. Males developed faster than females during 187.53 and 208.81 days, respectively. Females lived for longer times than males (i.e. 60.00 and 45.53 days, respectively). Life span was recorded as 268.8 and 233.1 days for females and males, respectively (Table 1). Survival ratio of individuals reached maturity was $72 \%$. Sex ratio under these rearing conditions was 0.682 females/total.

Although this species has a vast worldwide distribution as building hold one, it was not previously reared. Females deposited their eggs in a basket of webbing, and carried it all around through eggs incubation period (Figs. 1 and 3). Newly hatched spiderlings are very transparent and delicate (Fig. 5). These hatch stay in the basket and molt inside it or shortly after getting out of it without feeding on any prey. Males (Fig. 2) can mate for more than one time. They escape away from females after mating, otherwise they will be prayed on, if they were slugish. Early stages prefer to hunt small ants. They can hunt them in a wonderful way in a very short time. Also, they can hunt small flying insects which are prober to their size. Later stages can hunt larger prey type. Activity area of this species is relatively small. More than one individual can occur in small area.

\section{Biological aspects:}

Biological aspects of $M$. fauroti, at $26 \pm 2^{\circ} \mathrm{C}$ and $75 \pm 10 \%$ R.H. reared on T. urticae motile stages and E. kuehniella moths are presented in Tables (1-3). Durations in days of different stages are presented in Table (1). This spider went through eight spiderlings to reach adult as female and seven ones as male. Males developed faster than females during 187.53 and 208.81 days, respectively. Females lived for longer times than males (i.e. 60.00 and 45.53 days, respectively). Life span was recorded as 268.8 and 233.1 days for females and males, respectively (Table 1). Survival ratio of individuals reached maturity was $72 \%$. Sex ratio under these rearing conditions was 0.682 females/ total.

M. fauroti different female stages specific data are presented in Table 2. Pre-oviposition period was relatively short as 5.1 days; while oviposition period lasted 44.9 days. Generation time expanded to 212.4 days producing 68.26 eggs/female. It was produced in mean of 4.02 sacs/female (Table 2). Mean number of eggs per sac varied with the sac number per female. It was $13.22 \mathrm{eggs} / \mathrm{sac}$ within the first one. This number was maximum within the second one as 22.44 then decreased to $14.51 \mathrm{eggs} / \mathrm{sac}$, in the third one.

Table (1): Developmental durations (days) of Micropholcus fauroti (Simon, 1887), different stages at $26 \pm 2^{\circ} \mathrm{C}$ and $75 \pm 10 \%$ R.H.

\begin{tabular}{lcccccc}
\hline \multicolumn{1}{c}{$\begin{array}{c}\text { Developmental } \\
\text { Stage }\end{array}$} & Mean & S.D. & Range & Mean & S.D. & Range \\
\cline { 2 - 7 } & 10.49 & 1.39 & $8-13$ & 10.47 & 1.42 & $8-13$ \\
\hline Incubation period & 3.93 & 1.28 & $2-6$ & 4.12 & 1.36 & $2-6$ \\
\hline 1st spiderling & 9.16 & 1.41 & $8-12$ & 9.88 & 1.36 & $8-12$ \\
\hline 2nd spiderling & 13.88 & 2.22 & $12-20$ & 16.41 & 2.96 & $12-20$ \\
\hline 3rd spiderling & 20.00 & 2.95 & $16-24$ & 24.24 & 3.19 & $18-29$ \\
\hline 4th spiderling & 26.63 & 3.12 & $19-35$ & 34.24 & 3.07 & $28-38$ \\
\hline 5th spiderling & 34.23 & 2.87 & $21-40$ & 39.47 & 1.23 & $35-40$ \\
\hline 6th spiderling & 41.98 & 2.23 & $40-50$ & 48.71 & 0.99 & $48-50$ \\
\hline 7th spiderling & 48.51 & 1.88 & $47-55$ & -- & -- & -- \\
\hline 8th spiderling & 198.33 & 7.34 & $187-220$ & 177.06 & 7.00 & $165-185$ \\
\hline Total spiderlings & 208.81 & 7.10 & $201-230$ & 187.53 & 7.35 & $177-199$ \\
\hline Life cycle & 60.00 & 5.81 & $46-74$ & 45.53 & 4.48 & $38-52$ \\
\hline Adult longevity & 268.81 & 8.15 & $256-297$ & 233.06 & 7.46 & $216-245$ \\
\hline Life span & 19 & 2 & &
\end{tabular}

\footnotetext{
${ }^{1}$ Number of females sample was $43 . \quad{ }^{2}$ number of males sample was 20.
} 
Table (2): Female specific data of Micropholcus fauroti (Simon, 1887), at $26 \pm 2^{\circ} \mathrm{C}$ and $75 \pm 10 \%$ R.H.

\begin{tabular}{lccccccc}
\hline \multirow{2}{*}{\multicolumn{1}{c}{ Parameter }} & \multicolumn{3}{c}{ Durations or values } & \multicolumn{4}{c}{ Number of consumed } \\
& Mean & S.D. & Range & Mean & S.D. & Range & Daily rate \\
\cline { 2 - 9 } & 5.10 & 1.26 & $4-7$ & 17.85 & 4.25 & $13-26$ & 3.53 \\
\hline Pre-oviposition period & 44.88 & 5.83 & $35-55$ & 146.68 & 18.96 & $104-181$ & 3.28 \\
\hline Oviposition period & 212.419 & 7.75 & $196-237$ & -- & -- & -- & -- \\
\hline Generation time & 9.75 & 1.45 & $7-12$ & 10.6 & 2.41 & $8-15$ & 1.09 \\
\hline Post-oviposition period & 12.95 & 5.22 & $6-25$ & -- & -- & -- & -- \\
\hline Number of eggs/egg sac & 4.02 & 0.83 & $3-5$ & -- & -- & -- & -- \\
\hline Number of egg sacs/female & 68.26 & 12.28 & $50-85$ & -- & -- & -- & -- \\
\hline Number of eggs/female & & & & & & & \\
\hline
\end{tabular}

Table (3): Food consumption of Micropholcus fauroti (Simon, 1887), at $26 \pm 2{ }^{\circ} \mathrm{C}$ and $75 \pm 10 \%$ R.H.

\begin{tabular}{|c|c|c|c|c|c|c|c|c|c|}
\hline \multirow[b]{2}{*}{$\begin{array}{c}\text { Developmental } \\
\text { stage }\end{array}$} & \multirow[b]{2}{*}{ Prey } & \multicolumn{4}{|c|}{ Female } & \multicolumn{4}{|c|}{ Male } \\
\hline & & Mean & S.D. & Range & $\begin{array}{c}\text { Daily } \\
\text { rate }\end{array}$ & Mean & S.D. & Range & $\begin{array}{c}\text { Daily } \\
\text { rate }\end{array}$ \\
\hline $1^{\text {st }}$ spiderling & -- & -- & -- & -- & -- & -- & -- & -- & -- \\
\hline $2^{\text {nd }}$ spiderling & \multirow{3}{*}{$\begin{array}{c}\text { Tetranychus } \\
\text { urticae } \\
\text { motile stages }\end{array}$} & 47.63 & 10.51 & $32-70$ & 5.2 & 45.71 & 6.35 & $32-60$ & 4.64 \\
\hline $3^{\text {rd }}$ spiderling & & 89.18 & 22.67 & $48-128$ & 6.4 & 94.71 & 18.1 & $72-140$ & 5.83 \\
\hline $4^{\text {th }}$ spiderling & & 188.6 & 43.02 & $112-288$ & 9.39 & 205.29 & 35.75 & $126-252$ & 8.43 \\
\hline $5^{\text {th }}$ spiderling & \multirow{5}{*}{$\begin{array}{l}\text { Ephestia } \\
\text { kuehniella } \\
\text { moths }\end{array}$} & 26.95 & 5.34 & $18-36$ & 1.01 & 33.76 & 5.03 & $25-42$ & 0.98 \\
\hline $6^{\text {th }}$ spiderling & & 51.38 & 6.1 & $32-60$ & 1.5 & 68.06 & 7.06 & $58-81$ & 1.72 \\
\hline $7^{\text {th }}$ spiderling & & 88.2 & 7.77 & $76-103$ & 2.1 & 136.41 & 6.94 & $122-146$ & 0.18 \\
\hline $8^{\text {th }}$ spiderling & & 160.05 & 10.41 & $141-179$ & 3.3 & -- & -- & -- & -- \\
\hline Adult longevity & & 175.13 & 19.9 & $131-218$ & 2.93 & 69.88 & 8.98 & $84-56$ & 1.53 \\
\hline
\end{tabular}

Lowest numbers occurred in the last two ones as 8.56 and $6.00 \mathrm{eggs} / \mathrm{sac}$, respectively. Intervals between egg sacs deposition averaged 12.9 days. This mean number (12.95 eggs/sac) seemed to be low among spiders, but it can be explained by the caring mother behavior of carrying her egg sacs around the area until the eggs hatch and move out of the sac. This behavior maximizes the chance of newly emerged spiderlings survival, where they develop in a harsh type of environment.

\section{Life table parameters:}

Using the obtained biological and female specific data (Tables 1 and 2), life table parameters of $M$. fauroti (According to Birch, 1948) under these conditions were estimated as: mean generation time $(T)=232.2$ days, net reproductive rate $\left(R_{0}\right)=40.174$, intrinsic rate of increase $\left(\mathrm{r}_{\mathrm{m}}\right)=0.0159$ per day, and $\exp \left(\mathrm{r}_{\mathrm{m}}\right)=1.016$ individual/individual/day. As this organism is slow developer, these parameters can be presented per month as: $\mathrm{T}=7.74$ months, $\mathrm{r}_{\mathrm{m}}=0.477$ per month and $\exp \left(\mathrm{r}_{\mathrm{m}}\right)=1.611$ individual/individual/ month.

Food consumption of $M$. fauroti different stages is presented in Table (3). First spiderling was noticed to molt for the following one without feeding. In this study second to fourth spiderlings were reared on $T$. urticae motile stages; while fifth to eighth stage of females and seventh ones for males on adult moth of
E. kuehniella (Table 3). Mean consumption of T. urticae motile stages were 325.4 and 345.7 during second to fourth spiderlings for females and males, respectively. Mean consumption E.kuehniella females and males were 326.58 and 238.23 moths, respectively, during fifth spiderling to adult stage. Mean consumption of E. kuehniella for females and males was 175.1 and 69.88 moths, respectively, during adult stage longevity (Table 3 ).

\section{ACKNOWLEDGMENTS}

The authors are indebted to Col. Hisham K. ElHennawy (Cairo) who identified the spider species.

\section{REFERENCES}

Birch, L. C. 1948. The intrinsic rate of natural increase of an insect population. J. Animal Ecology, 17: 15-26.

Barrion, A.T.; S. S. Villareal; J. L. A. Catindig; D. Cai; Q.H. Yuan and Heong K.L. 2012. The spider fauna in the rice agricultural landscape of Hainan Island, China: composition, abundance and feeding structure. Asia Life Sciences, 21:625-651.

El-Hennawy, H. K. 2006. A list of Egyptian spiders (revised in 2006). Serket, 10(2):65-76.

Foelix, R. F. 2011. Biology of spiders. Third edition. Oxford Univ., 432 pp. 
Huber, B. A. 2003. High species diversity in one of the dominant groups of spiders in East African Mountain Forests (Araneae: Pholcidae: Buitinga n. gen., Spermophora Hentz). Zool. J. Linn. Soc., 137:555-619.

Huber, B. A.; Pérez, G., A. and Baptista, R. L. C. 2005. Leptopholcus (Araneae: Pholcidae) in continental America: rare relicts in low precipitation areas. Bonner Zool. Beitr., 53: 99-107.

Huber, B. A. and El-Hennawy, H. K. 2007. On old world ninetine spiders (Araneae: Pholcidae), with a new genus and species and the first record for Madagascar. Zootaxa, 1635: 45-53.

Huber, B. A.; Neumann, J.; A. Grabolle and Hula, V. 2017. Aliens in Europe updates on the distributions of Modisimus culicinus and Micropholcus fauroti (Araneae, Pholcidae). Arachnologische Mitteilungen/ Arachnology Letters, 53: 12-18.

World Spider Catalog. 2017. World spider catalog. Natural History Museum Bern. Online at http://wsc.nmbe.ch, version 18.0. accessed on September 5, 2017. 